\title{
Safe technologies for cutting reinforced concrete structures by means of diamond tools
}

\author{
Vasiliy Shalenny ${ }^{*}$ \\ Academy of Construction and Architecture of the Federal State Autonomous Educational Institution \\ of Higher Education «V.I.Vernadsky Crimean Federal University», Kievskaya street, 181, \\ Simferopol, 295493, Russia
}

\begin{abstract}
The advantages and the need to improve the safety of work when using modern diamond technologies for cutting concrete and reinforced concrete structures which are common during the dismantling and reconstruction of civil objects are shown. Improved organizational, structural and technological schemes of cutting these structures with diamond disc and wire saws with remote control are reasonably proposed. Preliminary fastening of cut elements on independent spatial scaffolding with screw jacks is a distinctive feature of the proposed schemes. In case of reconstruction by means of a device or an increase of the size of openings in load-bearing reinforced concrete and stone walls, a preliminary installation and commissioning of reinforcement steel frames provided for by the project are proposed, on them - guides of diamond disc, chain or wire saws and only then - cutting of reinforced concrete with its forced canting outside the working area for recycling.
\end{abstract}

\section{Introduction}

Today the problems of ensuring complex life safety occupy one of the central places in construction science and practice [1] including such rather complex and less studied stages of the life cycle of construction objects as their reconstruction and liquidation.

Modern technologies for cutting reinforced concrete and stone structures by means of diamond tools, unlike traditional methods using jackhammers and other crushing and squeezing equipment [2], minimize the level of noise, dust and vibration, as well as falling and spread of materials - products of disassembly or destruction.

This meets the modern requirements of 'green building' [3, 4], ergonomics, industrial and environmental safety $[5,6]$ of the construction and reconstruction of civil objects.

The use of modern diamond equipment with electric and hydraulic actuators technologies allow you perform work remotely, at a safe distance for the performers.

At the same time, many production workers using the above-mentioned varieties of both outdated and already modern diamond equipment of foreign origin quite often do not think about the consequences of dismantling works without a quality project, sometimes forgetting about the requirements of labor protection, safety of workers and environmental protection.

\footnotetext{
* Corresponding author: v_shalennyj@ mail.ru
} 
Specialists know previously developed constructive-technological solutions that ensure both safe performance of such works and subsequent long-term trouble-free operation of reconstructed construction sites $[7,8]$.

We have previously worked out options for the use of cutting technologies by means of diamond tools for disassembling reinforced concrete and stone structures of emergency facilities in Yalta.

We have already proposed fastening the guide of a diamond disc saw not on the structure to be cut but on special supporting independent equipment [9].

Such solutions exclude the possibility of spontaneous uncontrollable collapse of the elements of a structure being cut thereby increasing the safety of reconstruction or liquidation works which is reflected in the article [10].

In the former USSR and the Russian Federation, the theoretical foundations and experience of practical use of equipment for cutting concrete and reinforced concrete structures by means of diamond tools are summarized in the well-known works of Zhadanovsky B.V., PhD in Technical Sciences, and Sinenko S.A., Doctor of Technical Science $[11,12]$.

However, these works do not pay much attention to the matters of technology and safe organization of work using modern diamond cutting machines for such structures especially in conjunction with organization of safe extraction of disassembly products, as well as installation of metal structures of project reinforcement of the resulting opening.

Moreover, over the past period there have been significant changes in the supply of hydraulic equipment for cutting by means of diamond tools - wire and circular saws of foreign origin have become available to the production workers accumulating both positive and unfortunately negative experience of using this equipment during reconstruction work with replanning of civil objects. Indeed, for example, the instruction manual for diamond wire saws from a well-known manufacturing company, available on the Internet, does not contain exhaustive recommendations for safe performance of such works [13] but in practice contracting organizations very often perform work on the arrangement or increase of the size of wall openings and partitions without any prior unfastening and necessary elements of temporary or permanent reinforcement (Fig. 1).

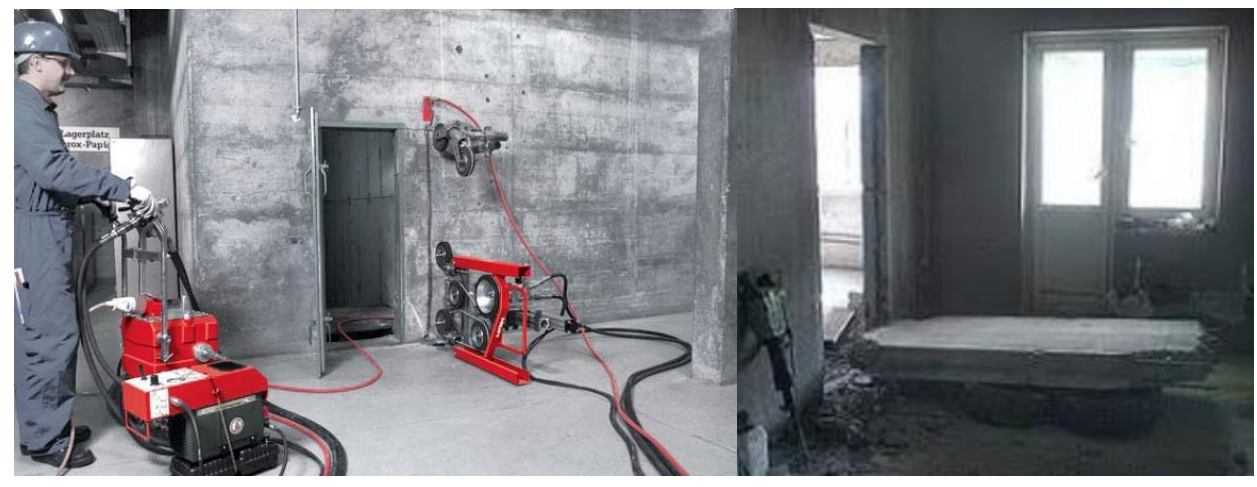

Fig. 1. Examples of unsafe increase in the width of opening in a stone wall with a wire diamond saw without its preliminary unloading and reinforcement.

Consequently, practical implementation of safe technology and organization of processes of cutting of building structures when disassembling and reconstructing specific objects using relatively new, highly productive and most importantly fundamentally capable of providing the necessary level of safety and manufacturability equipment for cutting by means of diamond tools, with electric and hydraulic actuator and its remote control still remains quite relevant scientific and applied problem. 


\section{Methods}

The above analysis of the state of the issue of safety of works on cutting by means of diamond tools taking into account the existing experience, including the negative one, of demolition and reconstruction of civil objects predetermined ways of possible improvement of the technology. They consist in preliminary design of a temporary stable and reliable organizational-constructive-technological system capable of preserving its geometric unchangeability under the influence of all possible and random factors arising in the process of such reconstruction works.

On this theoretical basis, fundamentally safe structural and technological schemes of cutting by means of diamond tools of horizontally and vertically arranged structural elements made out of concrete and reinforced concrete are generated, analyzed and selected.

Substantiation and presentation of the essence of such schemes is the main content and results of this work.

\section{Results}

The world's most famous manufacturers of diamond equipment such as Hilti, Hydrostress, Tyrolit and Cedima in the construction market offer a wide range of wall saws which in principle represent a modular system consisting of a guide post, head with hydraulic actuators located on it and compact, mainly electro-hydraulic oil station with a remote control.

As already mentioned, manufacturers' manuals recommend to fasten the guide post exclusively on the structure to be cut.

Not in all cases, such a process can be carried out in a completely safe mode.

Indeed, in the process of cutting the section of the structure will decrease until a crack appears, one part separates from the other and it is likely that some of them will turn or fall down. Or the saw blade may be clamped between the parts mentioned.

Theoretically, this could create an emergency situation threatening the collapse of the construction, damage to the equipment itself, and most importantly, to the life and health of workers.

In order to exclude such a completely probable and not safe process, further development of cutting technology with the use of unconditionally advanced equipment for diamond cutting is proposed.

Therefore, the essence of the proposed improved method of performing works on cutting horizontal bearing structures by means of diamond tools consists in preliminary fastening the guides of the diamond disc saw both on the structure to be cut and on supporting temporary elements of the independent fastening system based on scaffolding.

Constructive-technological schemes explaining and practically implementing such a principle are presented in Fig.2.

Before starting the process of cutting horizontal reinforced concrete beams in transportable elements, spatial independent scaffolding with screw jacks at the bottom and fork ends at the top are rolled under them. Independent beams of modern formwork dismountable and retractable systems for the installation of overlaps are installed into the above-mentioned forks, and then, through the said beams, the beam to be cut is jacked up.

Consequently, even before the start of separation of one part of the structure from another, they are already resting in a safe, stable state on the scaffolding. And their strapping is not necessary, but can be carried out after cutting as shown in Fig.2a. 


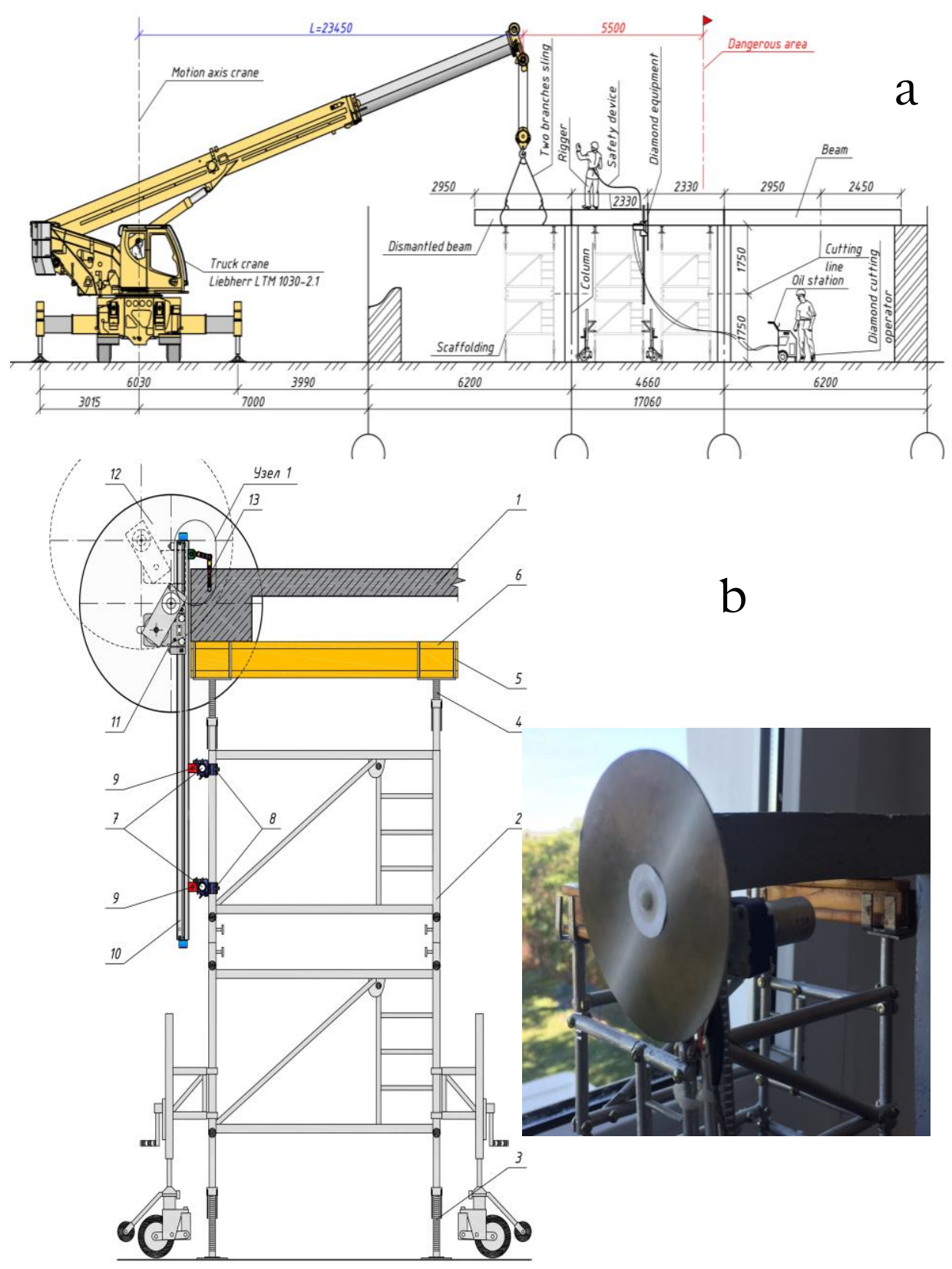

Fig. 2. Technological scheme of cutting and extracting parts of the overlap structures (a), as well as installing, fastening and moving the diamond disc saw on supporting independent spatial scaffolding (b): 1 - structure to be cut; 2 - scaffoldings with screw jacks in lower 3 and upper 4 parts of them; 5 fork, 6 - beam; 7, 8, 9 - connecting fastening elements of guide 10 of diamond disc saw 11 with cutting disk 12;13 - fastening elements of guide 10 in construction 1. 
During reconstruction with re-profiling of construction objects, a device or an increase in the size of openings in the supporting walls and partitions is often projected.

Such a weakening of the supporting structure requires both a preliminary temporary hanging of the upstream elements and a subsequent installation and commissioning of steel strapping frames for reinforcing the opening formed by cutting. 1).

In practice, we often witness ignoring of this obvious security requirement (see Figure

Our proposals for pre-assembling the specified steel frame on the one hand of the future opening with subsequent installation and rearrangement of the guides of the diamond disc saw on the other side partially solve the problem of unconditional fulfillment of work safety requirements [14].

This technology involves subsequent production of horizontal and vertical cuts, removal of cutting wastes, and only then - installation and commissioning of the rest elements of the construction of the reinforcement of the large-size opening arranged in this way.

Preliminary installation and commissioning of the entire projected frame reinforcement system, in this case, are difficult because of the need to use diamond discs of significantly larger diameter.

In addition, the task of removing large-sized cutting wastes remains unresolved.

In order to economically implement such a theoretically safe technology for constructing large-size openings in load-bearing walls and partitions, it is wise to use not disc, but wire diamond saws which have practically no restrictions on the thickness of the walls of the reinforced concrete structures of civil objects being cut.

At the same time, it is possible to solve the aforementioned problem of safe removal of cutting wastes of reinforced concrete wall structures.

Patented constructive and technological scheme of diamond cutting with a wire and safe removal of its wastes from the working area is presented in Fig.3.

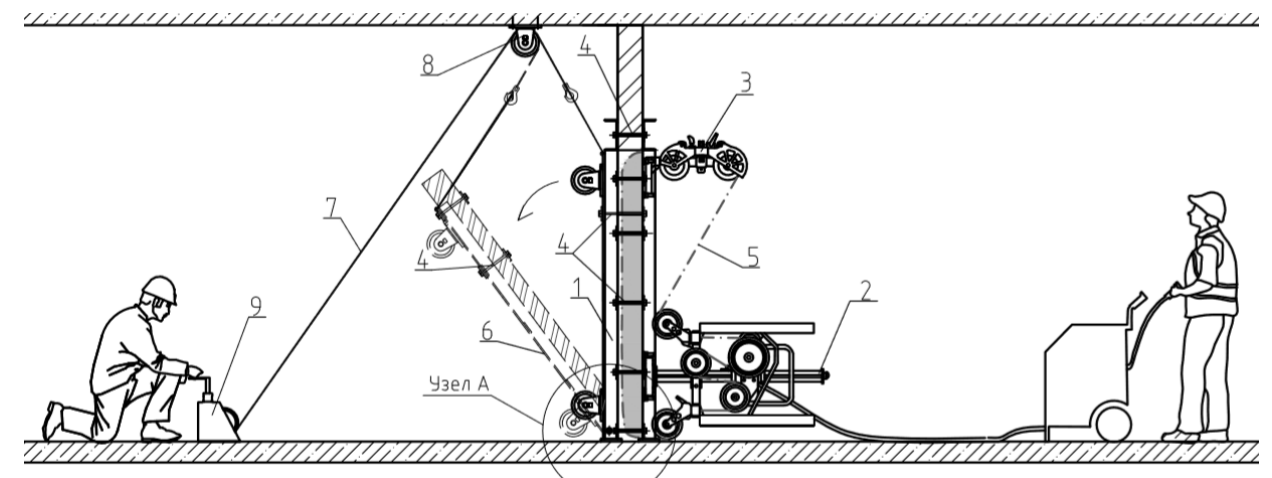

Fig. 3. Scheme of preliminary installation of steel frame of reinforcement and production of vertical cut with a diamond wire saw with remote control: 1 - part of the wall being cut on articulated and turntable platform 6;2 - sheave wheel and accumulator; 3 - base plate, 4 - bolted connections through via holes in wall and channels of the reinforcement frame; 5 - diamond cutting wire rope; 7 rope, 8 - sheave wheel; 9 - winch.

Alternatively, even before mounting the steel frame of reinforcement of the future opening, one can make a lower horizontal cut, and then install the specified frame.

In order to mount the reinforcement frame and immediately put it into operation, through holes are drilled by a template, pre-made markings or through holes in the resting against the wall frame of reinforcement of the future opening. 
In these holes threaded connections are made so that the reinforcement steel frame is fixed on the wall, and at the same time, on one side of the wall, supporting roller stands and a diamond wire saw are mounted which are also attached to the wall by means of similar threaded connections.

Then, in the corners of the future opening, through holes are drilled.

The diamond wire is passed into these holes at two points located within the boundaries of the cut, as well as through the supporting roller stands, after that it is laid on the back rollers and drive wheel of the diamond wire saw.

The project bearing system has been created and the cutting of the bearing reinforced concrete or stone wall in its lower part (lower horizontal cut) is made now.

Next, saw 2 with guides 3 are moved to the other vertical part of frame 4 on one of its side, and on the opposite side, using connecting pins 4 with washers, articulated and turntable platform 6 with wheels is mounted.

Using winch 9 with rope 7 and sheave wheel 8, by turning on pins, articulated and turntable platform 6 is brought to vertical position, as shown in Fig. 3.

In the part of opening which is to be cut out, holes are drilled and through them, by means of threaded connections, this part of opening which is to be cut out is pre-fixed on platform 6.

Now the necessary vertical and then the upper horizontal cut can be made absolutely safely, similarly sequentially moving and fixing guides 3 and saws 2 on frame 6 .

After opening 2 had been cut out this way, one should start extracting the cut part of it from wall 3.

For this purpose, by means of cable of winch, through sheave wheel, by turning around pin hinges, they move (cant) platform 6 together with the cut out part of opening fixed with threaded connections in a horizontal position where it comes to be on rollers.

Then pins and washers can be pulled out; after that platform 6 with the cut out part of opening of wall can be transported by means of rollers away from the work area for recycling.

The intermediate inclined position of the platform with the cut out part of the reinforced concrete wall construction is shown in Fig. 3 in dotted line.

\section{Discussion}

The presented constructive-technological schemes fundamentally improve the conditions for the performance of works on cutting of reinforced concrete structures by means of diamond tools in the direction of increasing their safety for the following reasons.

Cutting of horizontally placed overlaps located on pre-mounted and jacked up spatial scaffolding virtually eliminates the spontaneous separation and fall of both elements to be cut and adjacent elements.

This ensures technical stability and geometric immutability of the temporarily remaining part of the dismantled structure.

In addition, the application of this method can give a positive economic effect since it allows maximally preserve and, consequently, reuse reinforced concrete and concrete structures.

Due to this, it is possible to partially cover the costs of carrying out works on liquidation of objects.

Compared with the demolition of houses of the first mass series with the help of mounted hydraulic equipment of crushing type on excavators, the costs of recycling of the wastes of demolition are also reduced.

There will be much less noise, dust and rubbish which adversely affect the surrounding urban environment. 
In the other technological scheme presented, the diamond wire saw is first fixed directly on the structure to be cut to make the lower horizontal cut (as provided for by the manufacturer's instructions), thereby achieving the most efficient use of the diamond wire saw, and for subsequent cuts, the saw is mounted on pre-mounted elements of the reinforcement frame.

This technically ensures the required safety of work on arrangement of large-size openings in the bearing stone and reinforced concrete walls.

It becomes possible to reduce the number and length of cuts which has a positive effect on the timing and utilization of resources, primarily consumables, electricity and water.

Simple fixing elements will have to be added to the delivery set of diamond disc wall saws.

Installing the base plate and roller holders of the diamond wire saw not on the structure to be cut, but on the pre-mounted steel frame of reinforcement of the future opening involves simple updating of these elements in the delivery set of similar wall saws which can be done both by order of the contracting company itself and by the engineering plantmanufacturer.

\section{Conclusions}

Thus, reasonably proposed and comprehensively presented for the first time organizational, constructive and technological solutions for improving the methods of fastening modern diamond disc and wire saws before cutting operations, when used, will reliably ensure the safety of demolition of reinforced concrete structures.

The safety of reconstruction of buildings with arrangement of large-size openings in the bearing stone and reinforced concrete walls is also increased, and not only when performing the above works, but also during subsequent long-term use of building objects modernized in terms of replanning.

As a supervisor of master's theses, I express my gratitude to Pokotilo Dmitrii, Zagorodnii Vladimir and Shchegula Roman for their creative contribution to the development of the presented constructive-technological schemes for the safe use of diamond cutting equipment.

\section{References}

1. Telichenko, V.I. Safety of the living environment // Vestnik MGSU. - 2019. - V.14. Extr. 1. - P.11. DOI: 1022227/1997-09.35.2019.1.11.

2. Reconstruction of industrial enterprises. In 2 volumes. V. 2/V.D. Topchii, R.A. Grebennik, V.G. Klimenko and colleagues. - M.: Stroiizdat, 1990. - p.623, P.380-434.

3. Telichenko, V.I. From the principles of sustainable development to 'green' technologies // Vestnik MGSU. - 2016. - №11. - P.5-6.

4. Telichenko, V.I. 'Green' technologies of the living environment: concepts, terms, standards // Vestnik MGSU. - 2017. - V. 12. - Extr. 4(103). - P.364-372. DOI: 1022227/1997-09.35.2017.4.364-372.

5. Volkov, A.A., Tuskaeva, Z.R. Ergonomics and environmental safety - factors necessary to improve the competitiveness of domestic construction equipment // Vestnik MGSU. - 2017. - V. 12. - Extr. 3(102). - P.308-316.

6. Travush, V.I., Emelianov, S.G., Kolchunov, V.I. Safety of the living environment meaning and objectives of construction science // Industrial and civil construction. 2015. - №7. - P.20-27. 
7. Malganov, A.I. Restoration and strengthening of building structures of emergency and reconstructed buildings. Atlas of diagrams and drawings /A.I. Malganov, V.S. Plevkov, A.I. Polishchuk. - Tomsk, Center of National Technology Initiatives. - 1990. - p.320.

8. Koloskov, V.N. Dismantling of residential buildings and recycling of their structures and materials for reuse /V. N. Koloskov, P. P. Oleinik, A. F. Tikhonov. - M.: Publishing House ASV, 2004. - p.200.

9. Shalenny, V. T. Expansion of technological capabilities of diamond equipment for cutting structures by mounting on scaffolding /V.T. Shalenny, D.S. Pokotilo //Construction and technological safety. Collection of research papers. - Simferopol: National Academy of Environmental and Resort Construction, 2014. - Extr. 49. P.84-88.

10. Shalenny, V.T. Safe use of equipment for diamond cutting of reinforced concrete and stone structures //Construction materials, equipment, technologies of the XXI century. - 2017. - №9-10 (224225). - P.41-43.

11. Zhadanovskiy, B.V. Processing of materials with diamond disc tools. //Industrial and civil construction. 2004. - No.8. - P.18-19.

12. Zhadanovskiy, B.V., Sinenko, S.A. Peculiarities of arrangement of openings in reinforced concrete structures. //Scientific review. 2016. - №7. - P.39-42.

13. https: //www.hilti.ru/medias/sys_master/documents/h8c/9196083216414/OperatingInstruction-DSW-1005-E-01-Operating-Instruction-PUB-5312019-000.pdf.

14. Pat. No. 173168 U1, Russian Federation, IPC E04G23/02, B28D1/04, E04B1/35 (2006.01). Device for making a large-size opening in a bearing reinforced concrete or stone wall /V.T. Shalenny, V.S. Zagorodny. - application No.2017106511. - Appl. 02/27/2017; publ. 08/15/2017, Bull. No. 23. 